\title{
Incidence and outcome of newly-diagnosed tuberculosis in schizophrenics: a 12-year, nationwide, retrospective longitudinal study
}

\author{
Shu-Chen Kuo ${ }^{1,2,3 \dagger}$, Yung-Tai Chen ${ }^{4,5 \dagger}$, Szu-Yuan Li ${ }^{1,4}$, Yi-Tzu Lee ${ }^{1,2,6}$, Albert C Yang ${ }^{7,8}$, Te-Li Chen ${ }^{1,2^{*}}$,
} Chia-Jen Liü ${ }^{9,10,11}$, Tzeng-Ji Chen ${ }^{12}$, Ih-Jen Su ${ }^{3}$ and Chang-Phone Fung ${ }^{1,2}$

\begin{abstract}
Background: To control tuberculosis (TB), it is critical to identify at risk populations. Schizophrenia is recognized as an important risk factor for TB. However, previous studies have been confounded by comorbidities, and reports of TB infection outcomes are rare. Therefore, the current nation-wide study aimed to compare the adjusted incidence and outcome of TB diseases in schizophrenics and the general population.

Method: Using the National Health Insurance Research Database from 1998 to 2009, this retrospective longitudinal study included 60,409 schizophrenics and general population matched for age, Charlson's score, and comorbidities. Diagnosis of TB was based on the international classification of disease, ninth revision and use of anti-TB drugs. Unfavorable outcome for TB was defined as death, loss to follow-up, or use of anti-TB treatment for more than 9 months.

Results: The adjusted incidence of TB in schizophrenics was significantly higher than in the general population [hazard ratio, 1.52; 95\% confidence interval (Cl), 1.29-1.79; $p<0.001$; Kaplan-Meier log-rank test, $p<0.001$ ]. Cox regression revealed age and male gender as risk factors for newly-diagnosed TB. The outcome of TB was comparable in schizophrenics and the general population [odds ratio (OR), 0.78; 95\% Cl, 0.55-1.09; $\mathrm{p}=0.144$ ]. Logistic regression revealed a statistical trend for diabetes mellitus to predict poor outcome in schizophrenics with TB $(\mathrm{OR}, 2.30 ; 95 \% \mathrm{Cl}, 0.96-5.74 ; \mathrm{p}=0.062)$.

Conclusions: Schizophrenics are at increased risk for TB, and screening may be warranted for those living in areas with high prevalence of TB.
\end{abstract}

Keywords: Schizophrenia, Tuberculosis, Incidence, Outcome

\section{Background}

Tuberculosis (TB) remains the most prevalent infectious disease and the major leading cause of death worldwide, accounting for more than 9 million new cases and 1.4 million deaths [1]. The World Health Organization's "Global Plan to Stop TB" aims to eradicate this disease by 2050. An important strategy to control TB infection is to identify high-risk groups [2]. In addition to well-known

\footnotetext{
*Correspondence: tecklayyy@gmail.com

${ }^{\dagger}$ Equal contributors

${ }^{1}$ Institute of Clinical Medicine, National Yang-Ming University, School of Medicine, Taipei, Taiwan

2Division of Infectious Diseases, Taipei Veterans General Hospital, No. 201, Sec. 2, Shih-Pai Road, Taipei 112, Taiwan

Full list of author information is available at the end of the article
}

risk factors of TB, such as diabetes mellitus (DM) and human immunodeficiency virus (HIV), many studies have demonstrated an increased incidence of $\mathrm{TB}$ in schizophrenics [3-8]. Schizophrenia is a debilitating mental disease affecting $1 \%$ of the general population [9], and it is often accompanied by physical illnesses $[4,5,10]$ that may increase susceptibility to TB infection. However, previous studies have not adjusted for these confounding factors. In addition, outcomes for schizophrenics with concomitant TB have rarely been reported, though previous studies $[11,12]$ reported an increased risk of death due to TB in patients with mental illness. To adjust for confounding factors and determine outcomes in schizophrenics requires studies with larger sample sizes and longer follow-up than 
those previously conducted. Therefore, we conducted a nation-wide, retrospective longitudinal study that spanned 12 years and included 120,818 people to compare the adjusted incidence and outcome of TB diseases in schizophrenics and the general population.

\section{Methods}

\section{Data source}

Taiwan regulations stipulate mandatory registry and treatment of TB via the Directly Observed Treatment Short Course (DOTS) program, which is monitored by the Center for Disease Control (CDC, Taiwan). DOTS workers and public health nurses follow TB cases to monitor compliance and side effects, and they report directly to the local health authority. National Health Insurance (NHI) provides coverage for anti-TB treatment and monitors the cost. After its implementation by the government under the principle of mandatory and universal enrollment in 1995, the NHI program covered $99 \%$ of the population of Taiwan. Computerized claims data for inpatient and outpatient care, including demographic data, treatment, and diagnosis by international classification of disease, ninth revision (ICD-9-CM) [13], were collected and stored in the NHI Research Database (NHIRD), which is run by the National Health Research Institute. We retrospectively retrieved inpatient and outpatient claims data from NHIRD for the period of January 1998 to December 2009 to compare the incidence and outcome of newly-diagnosed TB in schizophrenics and controls.

As the data set used in our study consisted of deidentified secondary data released to the public for research purposes, studies of this kind were exempt from full review by the institutional review board.

\section{Definitions}

We performed a nation-wide study of schizophrenics and matched controls. The schizophrenic cohort comprised all patients who were admitted with schizophrenia (ICD-9-CM code 295.x) from January 1, 1998 to December 31, 2009. Schizophrenia diagnosis was further validated if it was coded by psychiatrists. The date of admission was considered the index date. Patients who were diagnosed with TB (ICD-9-CM codes 010.x to 018.x) before the index date were excluded.

Control subjects were selected from the Longitudinal Health Insurance Database dataset, which contains complete data of 1,000,000 randomly sampled beneficiaries from the original NHIRD. There were no significant differences in age or gender distribution in this sample of $1,000,000$ beneficiaries and the original NHIRD. We excluded those patients who were diagnosed with schizophrenia and antecedent TB (ICD-9-CM codes 010.x to 018.x). However, there were significant differences in age, gender, and comorbid disease between schizophrenics and controls. Thus, we further refined our control cohort criteria by randomly selecting subjects to match schizophrenic patients on age ( \pm 2 years), gender, index date, Charlson's score [13], chronic pulmonary disease, diabetes, and rheumatoid disease. To determine the incidence of TB, subjects were tracked from the index date until December 31, 2009, death, or diagnosis of TB. The diagnosis of new TB required the presence of ICD-9-CM code 010.x-018.x plus prescription of at least two anti-TB drugs (e.g., isoniazid, ethambutol, rifampin, pyrazinamide) for two months. Unfavorable outcomes included death, loss to follow-up, and prolonged treatment, which was defined as presence of ICD-9-CM code of TB for more than 9 months. Other comorbid diseases were retrieved by ICD-9-CM codes from the NHI database inpatient and outpatient datasets [13].

\section{Statistics analysis}

Pearson chi-square tests were used for categorical variables, while independent t-tests and Mann-Whitney $\mathrm{U}$ tests

Table 1 Baseline characteristics of schizophrenics and matched controls

\begin{tabular}{|c|c|c|c|}
\hline Characteristics & $\begin{array}{l}\text { Schizophrenics } \\
(n=60,409)\end{array}$ & $\begin{array}{l}\text { Controls } \\
(n=60,409)\end{array}$ & $P$ value \\
\hline Age, median & $35.4(26.9-44.9)$ & $35.3(26.3-45.3)$ & 0.001 \\
\hline Follow-up, days & $2,368(1,449-3,295)$ & $2,296(1,367-3,222)$ & \\
\hline Male & $33,271(55.1 \%)$ & $33,271(55.1 \%)$ & $>0.99$ \\
\hline \multicolumn{4}{|l|}{ Charlson's score } \\
\hline 0 & $37,186(61.6 \%)$ & $37,186(61.6 \%)$ & $>0.99$ \\
\hline $1-2$ & $19,216(31.8 \%)$ & $19,216(31.8 \%)$ & $>0.99$ \\
\hline$\geq 3$ & $4,007(6.6 \%)$ & $4,007(6.6 \%)$ & $>0.99$ \\
\hline $\begin{array}{l}\text { Chronic pulmonary } \\
\text { disease }\end{array}$ & $10,096(16.7 \%)$ & 10,096 (16.7\%) & $>0.99$ \\
\hline Diabetes & $5,179(8.6 \%)$ & $5,179(8.6 \%)$ & $>0.99$ \\
\hline Rheumatoid disease & $934(1.5 \%)$ & $934(1.5 \%)$ & $>0.99$ \\
\hline Peptic ulcer disease & $11,548(19.1 \%)$ & 10,901 (18.0\%) & $<0.001$ \\
\hline Liver disease & $7,796(12.9 \%)$ & $8,584(14.2 \%)$ & $<0.001$ \\
\hline Hypertension & $7,071(11.7 \%)$ & $6,903(11.4 \%)$ & 0.131 \\
\hline Arrhythmia & $6,420(10.6 \%)$ & $6,052(10.0 \%)$ & $<0.001$ \\
\hline Dyslipidemia & $4,988(8.3 \%)$ & $4,843(8.0 \%)$ & 0.127 \\
\hline Drug or substance abuse & $2,725(4.5 \%)$ & $13(0.02 \%)$ & $<0.001$ \\
\hline Chronic kidney disease & 1,812 (3.0\%) & $2,048(3.4 \%)$ & $<0.001$ \\
\hline Cancer & $1,282(2.1 \%)$ & $1,934(3.2 \%)$ & $<0.001$ \\
\hline Heart failure & $819(1.4 \%)$ & $861(1.4 \%)$ & 0.303 \\
\hline $\begin{array}{l}\text { Peripheral vascular } \\
\text { disease }\end{array}$ & $524(0.9 \%)$ & $484(0.8 \%)$ & 0.206 \\
\hline Myocardial infarction & $229(0.4 \%)$ & $318(0.5 \%)$ & $<0.001$ \\
\hline Hemiplegia or paraplegia & $147(0.2 \%)$ & $205(0.3 \%)$ & 0.002 \\
\hline$\overline{A I D S}$ & $53(0.09 \%)$ & $44(0.07 \%)$ & 0.361 \\
\hline
\end{tabular}

Data are median value (interquartile range) for continuous variables and number of cases (\%) for categorical variables. AIDS: acquired immunodeficiency syndrome. 
Table 2 Incidence and crude and adjusted hazard ratio of newly-diagnosed tuberculosis in schizophrenics and controls

\begin{tabular}{lllllll}
\hline & No. & Person-years & No. with TB & Incidence rate (per $\mathbf{1 0}^{\mathbf{5}}$ person-years) & Crude HR (95\% Cl) & Adjusted HR $\mathbf{~}^{\mathbf{9}} \mathbf{9 5}$ Cl) \\
\hline Total & 120,818 & 771,657 & 607 & 78.7 & & \\
\hline Schizophrenics & 60,409 & 392,109 & 366 & 93.3 & $1.48^{*}(1.26-1.74)$ & $1.52^{*}(1.29-1.79)$ \\
\hline Controls & 60,409 & 379,548 & 241 & 63.5 & Reference & Reference
\end{tabular}

${ }^{1}$ Adjusted HR was adjusted for age, sex, gender, Charlson's score and all comorbidities listed in Table 1. TB: tuberculosis, HR: hazard ratio, Cl: confidence interval. ${ }^{*} p<0.001$.

were used for parametric and nonparametric continuous variables, respectively. The incidence of $\mathrm{TB}$ diseases was compared by Poisson distribution method, and the cumulative incidence of TB diseases was compared by the Kaplan-Meier method (log-rank test). Risk factors with $\mathrm{p}$ values of $<0.1$ in univariate analysis were entered into the multivariate analysis. Multivariate Cox proportional hazard regression was performed using backward elimination to analyze independent risk factors for TB diseases. A $p$ value of $<0.05$ was considered significant.

\section{Results}

Baseline characteristics of schizophrenics

A total of 60,409 schizophrenics were included. The median follow-up period was 2,368 days (range, 1,449-3,295 days). Table 1 shows the clinical characteristics of this group. They were predominantly male $(33,271,55.1 \%)$, and the majority (93.4\%) did not have any severe comorbidities
(Charlson's score $<3$ ). The most prevalent underlying diseases were peptic ulcer diseases $(11,549,19.1 \%)$, chronic pulmonary diseases $(10,096,16.7 \%)$, and liver disease $(7,796,12.9 \%)$. A total of 60,409 controls were matched for gender, Charlson's score, chronic pulmonary disease, DM, and rheumatoid disease (All p > 0.99).

Higher incidence and risk factors of newly diagnosed TB cases in schizophrenics

There were 366 new TB cases among schizophrenics and 241 among controls during the total follow-up period of 771,657 person-years, as shown in Table 2 . The crude hazard ratio (HR) of TB diseases in schizophrenics was 1.48 [95\% confidence interval $(\mathrm{CI}), 1.26-1.74 ; \mathrm{p}<0.001$ ]. After adjusting for all variables in Table 1, the HR of TB in schizophrenics was 1.52 (95\% CI, 1.29-1.79; p < 0.001) compared with general population. As shown in Figure 1, Kaplan-Meier analysis also revealed a higher rate of

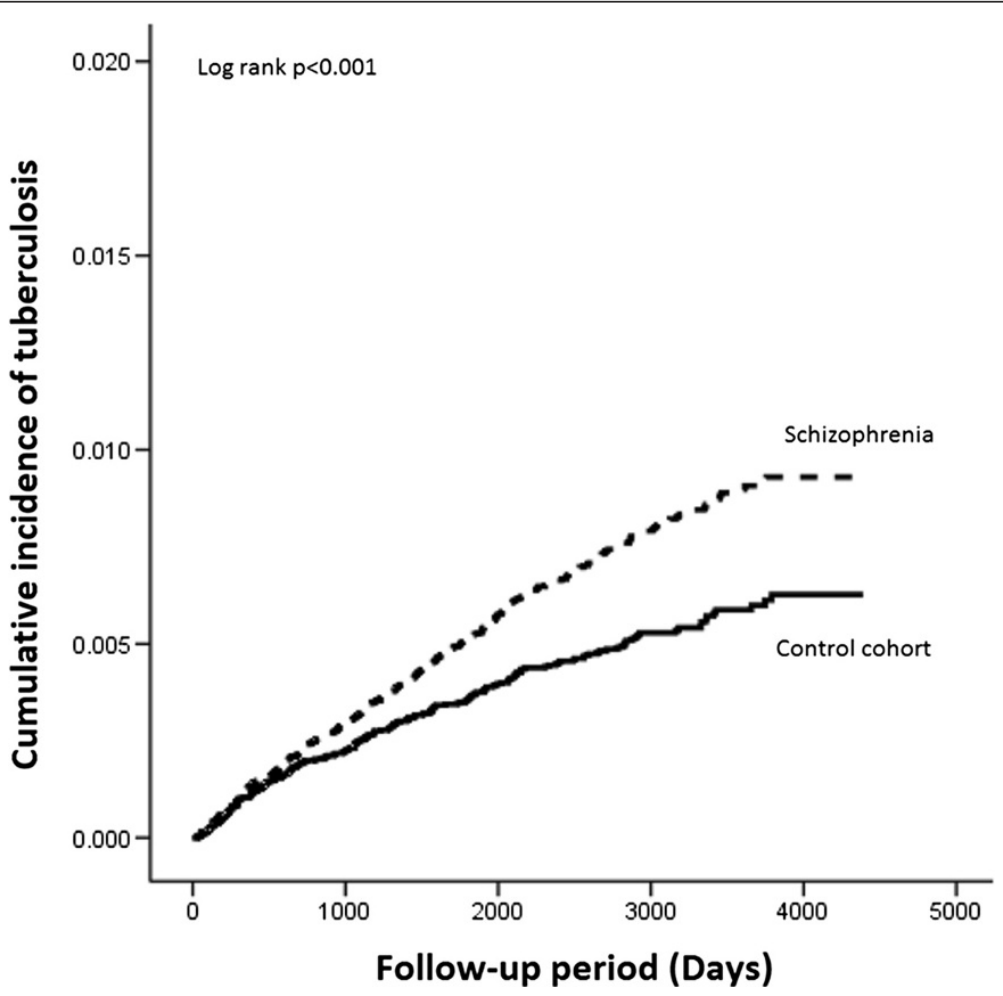

Figure 1 Kaplan-Meier plots of the cumulative incidence of tuberculosis between schizophrenics and control cohort. 
Table 3 Site of tuberculosis infection among schizophrenics and controls

\begin{tabular}{llll}
\hline Site of infection & $\begin{array}{l}\text { Schizophrenics } \\
(\mathbf{n}=\mathbf{3 6 6})\end{array}$ & $\begin{array}{l}\text { Controls } \\
(\mathbf{n}=\mathbf{2 4 1})\end{array}$ & P value \\
\hline Pulmonary & $321(87.7)$ & $206(85.5)$ & 0.502 \\
\hline Other respiratory & $16(4.4)$ & $16(6.6)$ & 0.299 \\
\hline $\begin{array}{l}\text { Skin, subcutaneous tissue, and } \\
\text { lymph nodes }\end{array}$ & $11(3.0)$ & $4(1.7)$ & 0.439 \\
\hline $\begin{array}{l}\text { Primary tuberculosis } \\
\text { Miliary tuberculosis }\end{array}$ & $10(2.7)$ & $6(2.5)$ & 0.920 \\
\hline $\begin{array}{l}\text { Meninges and central nervous } \\
\text { system }\end{array}$ & $2(0.5)$ & $2(0.8)$ & $>0.99$ \\
\hline $\begin{array}{l}\text { Intestines, peritoneum, and } \\
\text { mesenteric glands }\end{array}$ & $2(0.5)$ & $2(0.4)$ & $>0.99$ \\
\hline \begin{tabular}{l} 
Bones and joints \\
\hline Genitourinary system
\end{tabular} & $1(0.3)$ & $2(0.8)$ & 0.651 \\
\hline Dat & $2(0.8)$ & 0.157 \\
\hline
\end{tabular}

Data are number of cases (\%).

newly-diagnosed TB in schizophrenics (log-rank test, $\mathrm{p}<0.001)$. Most of the diseases were pulmonary in origin, occurring in 321 (87.7\%) schizophrenics and 206 (85.5\%) controls, as shown in Table $3(\mathrm{p}=0.50)$. Compared with schizophrenics without TB (Table 4), those with TB tended to have advanced age, male gender, higher Charlson's score, DM, myocardial infarction, and hypertension. Cox regression showed independent risks for newly-diagnosed TB to be age and male gender, while patients with hypertension were less likely to have new TB diseases.

\section{Comparable outcome of newly-diagnosed TB cases in schizophrenics and controls}

Unfavorable outcomes occurred in 138 (37.7\%) of 366 schizophrenics and in 105 (43.6\%) of 241 controls with new TB diseases [crude odds ratio (OR), 0.78; 95\% CI, 0.56-1.09; $\mathrm{p}=0.149$ ]. During anti-TB therapy, 26 (7.1\%) schizophrenics were lost to follow-up, 4 (1.1\%) died, and 108 (29.5\%) underwent treatment for more than 9 months. In the control group, 19 (7.9\%) were lost to follow-up, one died $(0.4 \%)$, and $85(35.3 \%)$ underwent treatment for more than 9 months (All p > 0.05). After adjusting for comorbidities, schizophrenics and controls with new TB diseases had comparable outcomes (OR, 0.78; 95\% CI, $0.55-1.09 ; \mathrm{p}=0.144)$. Multivariate analysis revealed a statistical trend for DM to predict poor outcome in schizophrenics (OR, 2.30; 95\% CI, 0.96-5.74; $\mathrm{p}=0.062$, Additional file 1: Table S1).

\section{Discussion}

Our nationwide study included a total of 60,409 schizophrenics and controls with a median follow-up duration

Table 4 Multivariate Cox regression of risk for newly-diagnosed TB in schizophrenics

\begin{tabular}{|c|c|c|c|c|c|c|}
\hline \multirow[t]{2}{*}{ Characteristics } & \multicolumn{3}{|c|}{ Univariate } & \multicolumn{3}{|c|}{ Multivariate* } \\
\hline & HR & $95 \% \mathrm{Cl}$ & $P$ value & HR & $95 \% \mathrm{Cl}$ & $P$ value \\
\hline Age, 1 year & 1.05 & $1.04-1.06$ & $<0.001$ & 1.06 & $1.05-1.06$ & $<0.001$ \\
\hline Male & 2.63 & $2.07-3.35$ & $<0.001$ & 3.13 & $2.46-3.99$ & $<0.001$ \\
\hline Charlson's score & 1.18 & $1.07-1.29$ & 0.001 & & & \\
\hline Diabetes & 1.77 & $1.29-2.43$ & $<0.001$ & & & \\
\hline Chronic pulmonary disease & 1.26 & $0.96-1.66$ & 0.097 & & & \\
\hline Rheumatoid disease & 1.51 & $0.71-3.18$ & 0.283 & & & \\
\hline Myocardial infarction & 4.70 & $1.94-11.37$ & 0.001 & & & \\
\hline Heart failure & 1.90 & $0.90-4.01$ & 0.094 & & & \\
\hline Peripheral vascular disease & 1.69 & $0.63-4.52$ & 0.298 & & & \\
\hline Peptic ulcer disease & 1.19 & $0.91-1.55$ & 0.203 & & & \\
\hline Liver disease & 1.05 & $0.76-1.45$ & 0.773 & & & \\
\hline Hemiplegia or paraplegia & 1.33 & $0.19-8.45$ & 0.777 & & & \\
\hline Chronic kidney disease & 1.14 & $0.61-2.13$ & 0.693 & & & \\
\hline Cancer & 1.62 & $0.87-3.05$ & 0.131 & & & \\
\hline Hypertension & 1.46 & $1.08-1.97$ & 0.013 & 0.68 & $0.49-0.93$ & 0.017 \\
\hline Dyslipidemia & 1.16 & $0.79-1.71$ & 0.45 & & & \\
\hline Arrhythmia & 0.91 & $0.62-1.33$ & 0.64 & & & \\
\hline Drug or substance abuse & 1.44 & $0.90-2.32$ & 0.13 & & & \\
\hline AIDS & 0.05 & $0.00-2556713$ & 0.74 & & & \\
\hline
\end{tabular}

HR: hazard ratio, Cl: confidence interval, AIDS: acquired immunodeficiency syndrome.

Only factors with $P$ value less than 0.1 in the univariate analysis were entered into the multivariate analysis and only factors with $P$ value less than 0.05 in multivariate analysis was presented. 
of 6 years. After adjusting for underlying diseases, schizophrenics had a higher incidence of newly-diagnosed TB, but comparable outcomes to the general population. Independent risk factors for TB in schizophrenics were age and male gender. A statistical trend was found for DM as an independent risk factor for unfavorable prognosis in schizophrenics with TB.

The increased prevalence of TB in schizophrenics [3-8] may be related to different incidences of physical comorbidities [5], which could influence the likelihood of TB diseases. The relative risk of DM and colon cancer in schizophrenics has been reported as 1.5-2.0 [14] and 2.9 [15], respectively, compared with the general population, while infection rate of HIV in mentally ill patients was $4-23 \%$ compared with $0.3 \%$ for the general population in an area with high prevalence [16]. To our knowledge, this study has the largest number of schizophrenic subjects and is the first matched retrospective longitudinal study of its kind, which enabled adjusting for comorbidities. After adjustment, the incidence of newly-diagnosed TB was 1.5 times higher in schizophrenics compared to the general population, lower than previously reported [3-8]. The reason for the higher risk of $\mathrm{TB}$ in schizophrenics is unknown. Development of TB has been associated with several biological and social factors $[1,17]$. By adjusting biological factors, our study may indicate behavior and socioeconomic factors play an important role $[17,18]$. First, overcrowding and close contact is an established risk factor for TB [19]. Josoph et al. recently reported an outbreak within an assisted living facility for adults with mental illness [20], concluding that elevated risk for TB disease among this population was due to sustained transmission in crowded settings. Second, mentally ill patients have higher levels of substance abuse, such as smoking or alcohol use [21], which has been associated with active TB diseases [1]. Third, the low socioeconomic status of this vulnerable population [22,23] may predispose them to TB diseases [24]. Fourth, poor communication skills in this group may prevent or delay diagnosis and management of physical diseases [25]. Unfortunately, the anonymous and hospital-based nature of the NHI database precluded collection of data related to socioeconomic status and whether subjects lived in community-based facilities. Further studies are needed to evaluate the influence of these behavioral and socioeconomic factors on incidence of newly-diagnosed TB cases in schizophrenics.

The relative risk of death due to TB in patients with mental illness has been decreasing from 7.0 in the $1930 \mathrm{~s}$ to 5.5 in the 1970s $[11,12]$. This has been attributed to improvements in treatment [3]. In our study, the rates of unfavorable outcomes for TB (mortality, loss to follow-up, and prolonged treatment) were comparable between schizophrenics and the general population after adjusting for comorbidities. This may be explained by coverage of
99\% of the population by Taiwan NHI, as well as policies by the Taiwan CDC for enhancing diagnosis, follow-up, and treatment $[26,27]$.

\section{Conclusions}

In conclusion, schizophrenics had a higher incidence of newly-diagnosed TB than the general population. Fortunately, with advances in treatment and support from the national health care system, outcomes from TB were comparable in schizophrenics and the general population.

\section{Consent statement}

As the data set used in our study consisted of de-identified secondary data released to the public for research purposes, the study was exempt from full review by the institutional review board.

\section{Additional file}

Additional file 1: Risk factor of unfavorable outcome of TB among schizophrenics.

\section{Abbreviations}

CDC: Center for disease control; Cl: Confidence interval; DM: Diabetes mellitus; DOTS: Directly observed treatment short course; HIV: Human immunodeficiency virus; HR: Hazard ratio; ICD-9-CM: International classification of disease, ninth revision; NHI: National health insurance; NHIRD: NHI Research database; OR: Odds ratio; TB: Tuberculosis.

\section{Competing interests}

The authors declare that they have no competing interests.

\section{Authors' contributions}

SCK, SYL, YTL, and ACY managed the literature searches, designed the study, and completed the draft of the manuscript. YTC, CJL, and TJC collected the data, organized the database, undertook data analysis, and interpreted the data. TLC, IJS, and CPF monitored this program and contributed to manuscript revisions and approved the final version. All authors contributed to and have approved the final manuscript.

\section{Acknowledgments}

The authors would like to thank the National Health Research Institute making their database available. This work was supported by grants from the National Health Research Institute (IV-101-PP-12), Taipei Veterans General Hospital (V101E4-003 and V101A-017), and the National Science Council (98-2314-B-010-010-MY3).

\section{Author details}

${ }^{1}$ Institute of Clinical Medicine, National Yang-Ming University, School of Medicine, Taipei, Taiwan. ${ }^{2}$ Division of Infectious Diseases, Taipei Veterans General Hospital, No. 201, Sec. 2, Shih-Pai Road, Taipei 112, Taiwan. ${ }^{3}$ National Institute of Infectious Diseases and Vaccinology, National Health Research Institutes, Miaoli County, Taiwan. ${ }^{4}$ Division of Nephrology, Taipei Veterans General Hospital, Taipei, Taiwan. ${ }^{5}$ Department of Medicine, Taipei City Hospital Heping Fuyou Branch, Taipei, Taiwan. ${ }^{6}$ Department of Medicine, Chutung Veterans Hospital, Chutung, Taiwan. ${ }^{7}$ Department of Psychiatry, Taipei Veterans General Hospital, Taipei, Taiwan. ${ }^{8}$ Division of Psychiatry, School of Medicine, National Yang-Ming University, Taipei, Taiwan. ${ }^{9}$ Institute of Public Health \& School of Medicine, National Yang-Ming University, Taipei, Taiwan. ${ }^{10}$ Division of Hematology and Oncology, Department of Medicine, Taipei Veterans General Hospital, Taipei, Taiwan. ${ }^{11}$ Department of Internal Medicine, National Yang-Ming University Hospital, Yilan, Taiwan. 
${ }^{12}$ Department of Family Medicine, Taipei Veterans General Hospital, Taipei, Taiwan.

Received: 28 August 2012 Accepted: 27 July 2013

Published: 29 July 2013

\section{References}

1. Lawn SD, Zumla Al: Tuberculosis. Lancet 2011, 378:57-72.

2. WHO: World Heath Organization. Global tuberculosis control: epidemiology, strategy, financing. 2009. Available at: http://www.who.int/tb/publications/ global_report/2009/en/. Accessed August 2012.

3. Ohta Y, Nakane Y, Mine M, Nakama I, Michitsuji S, Araki K, Tominaga Y, Uchino J: The epidemiological study of physical morbidity in schizophrenics-2. Association between schizophrenia and incidence of tuberculosis. Jpn J Psychiatry Neurol 1988, 42:41-47.

4. Baldwin JA: Schizophrenia and physical disease. Psychol Med 1979, 9:611-618.

5. De Hert M, Correll CU, Bobes J, Cetkovich-Bakmas M, Cohen D, Asai I, Detraux J, Gautam S, Moller H-J, Ndetei DM, Newcomer JW, Uwakwe R, Leucht S: Physical illness in patients with severe mental disorders. I. Prevalence, impact of medications and disparities in health care. World Psychiatry 2011, 10:52-77.

6. Mishin VI, Shevchuk El, Tsygankov BD, Losev LV: New-onset pulmonary tuberculosis patients with schizophrenia: course and efficiency of treatment. Probl Tuberk Bolezn Legk 2008, 6:6-10.

7. Fisher II, Bienskii AV, Fedorova IV: Experience in using serological tests in detecting tuberculosis in patients with severe mental pathology. Probl Tuberk 1996, 1:19-20.

8. Zeenreich A, Gochstein B, Grinshpoon A, Miron M, Rosenman J, Ben-Dov I: Recurrent tuberculosis in a psychiatric hospital, recurrent outbreaks during 1987-1996. Harefuah 1998, 134:168-172.

9. Freedman R: Schizophrenia. N Engl J Med 2003, 349:1738-1749.

10. Dixon L, Weiden P, Delahanty J, Goldberg R, Postrado L, Lucksted A, Lehman A: Prevalence and correlates of diabetes in national schizophrenia samples. Schizophr Bull 2000, 26:903-912.

11. Shinozaki H: An epidemiologic study of deaths of psychiatric inpatients. Compr Psychiatry 1976, 17:425-436.

12. Tsuang MT, Woolson RF, Fleming JA: Causes of death in schizophrenia and manic-depression. Br J Psychiatry 1980, 136:239-242.

13. Deyo RA, Cherkin DC, Ciol MA: Adapting a clinical comorbidity index for use with ICD-9-CM administrative databases. J Clin Epidemiol 1992. 45:613-619.

14. De Hert M, Dekker JM, Wood D, Kahl KG, Holt Rl, Moller HJ: Cardiovascular disease and diabetes in people with severe mental illness position statement from the European psychiatric association (EPA), supported by the European association for the study of diabetes (EASD) and the European society of cardiology (ESC). Eur Psychiatry 2009, 24:412-424.

15. Hippisley-Cox J, Vinogradova Y, Coupland C, Parker C: Risk of malignancy in patients with schizophrenia or bipolar disorder: nested case-control study. Arch Gen Psychiatry 2007, 64:1368-1376.

16. Carey MP, Carey KB, Kalichman SC: Risk for human immunodeficiency virus (HIV) infection among persons with severe mental illnesses. Clin Psychol Rev 1997, 17:271-291.

17. Kim S, Crittenden KS: Risk factors for tuberculosis among inmates: a retrospective analysis. Public Health Nurs 2005, 22:108-118.

18. Lienhardt C: From exposure to disease: the role of environmental factors in susceptibility to and development of tuberculosis. Epidemiol Rev 2001, 23:288-301.

19. Vynnycky E, Fine PE: Interpreting the decline in tuberculosis: the role of secular trends in effective contact. Int J Epidemiol 1999, 28:327-334.

20. Cavanaugh JS, Powell K, Renwick OJ, Davis KL, Hilliard A, Benjamin C, Mitruka K: An outbreak of tuberculosis among adults with mental illness. Am J Psychiatry 2012, 169:569-575.

21. Kendrick T: Cardiovascular and respiratory risk factors and symptoms among general practice patients with long-term mental illness. Br J Psychiatry 1996, 169:733-739.

22. Dohrenwend BP, Levav I, Shrout PE, Schwartz S, Naveh G, Link BG, Skodol $A E$, Stueve A: Socioeconomic status and psychiatric disorders: the causation-selection issue. Science 1992, 255:946-952.

23. Marwaha S, Johnson S: Schizophrenia and employment - a review. Soc Psychiatry Psychiatr Epidemiol 2004, 39:337-349.
24. Olson NA, Davidow AL, Winston CA, Chen MP, Gazmararian JA, Katz DJ: A national study of socioeconomic status and tuberculosis rates by country of birth, United States, 1996-2005. BMC Public Health 2012, 12:365.

25. De Hert M, Cohen D, Bobes J, Cetkovich-Bakmas M, Leucht S, Ndetei DM, Newcomer JW, Uwakwe R, Asai I, Moller HJ, Gautam S, Detraux J, Correll CU: Physical illness in patients with severe mental disorders. II. Barriers to care, monitoring and treatment guidelines, plus recommendations at the system and individual level. World Psychiatry 2011, 10:138-151.

26. Lo H-Y, Yang S-L, Chou P, Chuang J-H, Chiang C-Y: Completeness and timeliness of tuberculosis notification in Taiwan. BMC Public Health 2011, 11:915.

27. Li Y, Tsai W, Khan M, Yang W, Lee T, Wu Y, Kung P: The effects of pay-for-performance on tuberculosis treatment in Taiwan. Health Policy Plan 2010, 25:334-341.

doi:10.1186/1471-2334-13-351

Cite this article as: Kuo et al:: Incidence and outcome of newlydiagnosed tuberculosis in schizophrenics: a 12-year, nationwide, retrospective longitudinal study. BMC Infectious Diseases 2013 13:351.

\section{Submit your next manuscript to BioMed Central and take full advantage of:}

- Convenient online submission

- Thorough peer review

- No space constraints or color figure charges

- Immediate publication on acceptance

- Inclusion in PubMed, CAS, Scopus and Google Scholar

- Research which is freely available for redistribution 